\title{
Chemotherapy resistance and metastasis-promoting effects of thyroid hormone in hepatocarcinoma cells are mediated by suppression of Fox01 and Bim pathway
}

\author{
Hsiang-Cheng Chi ${ }^{1}$, Shen-Liang Chen ${ }^{2}$, Yi-Hung Cheng ${ }^{1}$, Tzu-Kang Lin ${ }^{3}$, Chung-Ying Tsai ${ }^{1}$, Ming-Ming Tsai ${ }^{4,5}$, Yang-Hsiang Lin ${ }^{1}$, \\ Ya-Hui Huang ${ }^{*, 6}$ and Kwang-Huei Lin ${ }^{*, 1,6}$
}

Hepatocellular carcinoma (HCC) is the third leading cause of cancer-related death worldwide, and systemic chemotherapy is the major treatment strategy for late-stage HCC patients. Poor prognosis following chemotherapy is the general outcome owing to recurrent resistance. Recent studies have suggested that in addition to cytotoxic effects on tumor cells, chemotherapy can induce an alternative cascade that supports tumor growth and metastasis. In the present investigation, we showed that thyroid hormone (TH), a potent hormone-mediating cellular differentiation and metabolism, acts as an antiapoptosis factor upon challenge of thyroid hormone receptor (TR)-expressing HCC cells with cancer therapy drugs, including cisplatin, doxorubicin and tumor necrosis factor-related apoptosis-inducing ligand (TRAIL). TH/TR signaling promoted chemotherapy resistance through negatively regulating the pro-apoptotic protein, Bim, resulting in doxorubicin-induced metastasis of chemotherapy-resistant HCC cells. Ectopic expression of Bim in hepatoma cells challenged with chemotherapeutic drugs abolished TH/TR-triggered apoptosis resistance and metastasis. Furthermore, Bim expression was directly transactivated by Forkhead box protein 01 (Fox01), which was negatively regulated by $\mathrm{TH} / \mathrm{TR}$. TH/TR suppressed Fox01 activity through both transcriptional downregulation and nuclear exclusion of Fox01 triggered by Akt-mediated phosphorylation. Ectopic expression of the constitutively active Fox01 mutant, Fox01-AAA, but not Fox01-wt, diminished the suppressive effect of TH/TR on Bim. Our findings collectively suggest that expression of Bim is mediated by FoxO1 and indirectly downregulated by $\mathrm{TH} / \mathrm{TR}$, leading to chemotherapy resistance and doxorubicin-promoted metastasis of hepatoma cells.

Cell Death and Disease (2016) 7, e2324; doi:10.1038/cddis.2016.227; published online 4 August 2016

Hormones are molecules produced by glands in the body that enter the bloodstream and influence the behavior of another group of cells located distally. Aberrant hormone levels are implicated in the formation of several cancers. For instance, excessive estrogen or progesterone is reported to promote cellular growth of breast and prostate tumors, with antiestrogen and progesterone currently used as the main treatment strategies for these cancer types. ${ }^{1,2}$ Thyroid hormones (TH), mainly 3,3'-5-tri-iodo-L-thyronine $\left(\mathrm{T}_{3}\right)$, are potent mediators of multiple physiological activities, including cellular differentiation, metabolic rate, digestive functions and lipid metabolism. ${ }^{3,4}$ The actions of $T_{3}$ are executed via binding to thyroid hormone receptor (TR) located in the nucleus. TRs are ligand-dependent transcription factors encoded by two genes, TRa and TR $\beta$. Upon binding of $\mathrm{T}_{3}$, TRs release associated co-repressors and recruit transcriptional co-activators to initiate target gene transcription. ${ }^{5}$ Liver is one of the major target organs of $T_{3}$, and body $\mathrm{TH}$ levels are closely correlated with multiple liver-associated diseases, such as hepatocellular carcinoma (HCC). ${ }^{6-9}$

In the diethylnitrosamine (DEN)-induced HCC animal model, ${ }^{10,11} \mathrm{~T}_{3}$ has been identified as a potent inhibitor of HCC development, although significant associated mitogenic effects on hepatocytes are reported. Conversely, in chemotherapyresistant populations of advanced HCC cells, TH/TR has been shown to promote tumor cell metastasis via upregulation of several extracellular matrix (ECM) proteases, such as matrix metalloproteinase (MMP)-2, -7 and $-9 .{ }^{12}$

The observed effects of TH/TR on HCC development signify hormone-mediated targeting of pathways leading to apoptosis to achieve stage-specific outcomes. The conserved intrinsic mitochondrial apoptosis pathway is controlled by interplay between subgroups of the Bcl-2 family, ${ }^{13}$ specifically, proapoptotic multi-domain, antiapoptotic and pro-apoptotic Bcl-2-

\footnotetext{
${ }^{1}$ Department of Biochemistry, College of Medicine, Chang-Gung University, Taoyuan 333, Taiwan; ${ }^{2}$ Department of Life Sciences, National Central University, Taoyuan 333, Taiwan, Republic of China; ${ }^{3}$ Division of Neurosurgery, Chang Gung Memorial Hospital Linkou and Chang Gung University, Taoyuan 333, Taiwan, Republic of China; ${ }^{4}$ Department of Nursing, Chang-Gung University of Science and Technology, Taoyuan 333, Taiwan; ${ }^{5}$ Department of General Surgery, Chang Gung Memorial Hospital Chiayi 613, Taiwan and ${ }^{6}$ Liver Research Center, Department of Hepato-Gastroenterology, Chang Gung Memorial Hospital, Linkou, Taoyuan 333, Taiwan

${ }^{*}$ Corresponding author: Y-H Huang or K-H Lin, Liver Research Center, Department of Hepato-Gastroenterology, Chang Gung Memorial Hospital, Linkou, 5 Fuxing St. Guishan Dist., Taoyuan 333, Taiwan or Graduate Institute of Biomedical Sciences, Chang-Gung University, College of Medicine, 259 Wen-Hwa 1st Road, Taoyuan 333, Taiwan; Tel: +886 3 2118263; Fax: +886 3 2118263. E-mail: e1249060@gmail.com or khlin@mail.cgu.edu.tw

Abbreviations: BH3-only, Bcl-2-homology domain 3 only; Bim, Bcl-2-interacting mediator of cell death; DEN, diethylnitrosamine; ECM, extracellular matrix; FoxO, transcription factors of the class $\mathrm{O}$; HCC, hepatocellular carcinoma; MMP, matrix metalloproteinase; PI3K, phosphatidylinositol 3-kinase; TH, thyroid hormone; TR, thyroid hormone receptor; TRAIL, tumor necrosis factor-related apoptosis-inducing ligand

Received 06.4.16; revised 21.6.16; accepted 28.6.16; Edited by G Raschella
} 
homology domain 3 only (BH3-only) proteins. The members of the $\mathrm{BH} 3-$ only subfamily of proteins share only the short $\mathrm{BH} 3$ domain with members of the Bcl-2 family. The expression patterns and activities of $\mathrm{BH}$-only proteins are strictly regulated through complex cellular signals at both the transcriptional and posttranscriptional levels. These proteins have significant roles in initiating various physiological apoptotic events, including developmentally programmed cell death and stress-associated apoptosis. ${ }^{13,14}$

$\mathrm{Bcl}-2$-interacting mediator of cell death $(\mathrm{Bim})$ is one of the $\mathrm{BH} 3-$ only proteins that exhibits potent ability to bind all antiapoptotic $\mathrm{Bcl}-2$ proteins with high affinity to trigger cell death. ${ }^{15}$ In addition to its intrinsic toxicity, alternative splicing generates a variety of Bim isoforms with different cellular toxicities and modes of regulation. ${ }^{16-18}$ Among these, Bim-EL, Bim- - and Bim-s, differing in proapoptotic activity, have been most extensively studied. In view of the finding that suppression of Bim promotes metastasis and chemoresistance of tumor cells, considerable research attention has focused on its utility as an inducer of cell death and thus a potential target for tumor therapy. ${ }^{19-21}$

Expression of Bim is mainly controlled by transcription factors of the class $\mathrm{O}$ (FoxO) of the Forkhead box-containing protein family. ${ }^{22,23}$ FoxO transcription factors, including FoxO1 (FKHR), FoxO3 (FKHRL1), FoxO4 (AFX) and FoxO6, bind DNA through a conserved forkhead box. They are additionally recruited to target sites through protein-protein interactions with other transcription factors, such as nuclear receptors, ${ }^{24}$ and are critical for various cellular physiological functions, including cell cycle regulation and apoptosis. ${ }^{25-27}$ Transactivational activity of these proteins on target genes is highly dependent on their subcellular localization. For instance, in cells where the PI3k-Akt pathway is activated, FoxO1 is phosphorylated at residues T24, S256 and S319 and later shuttled out of nucleus, resulting in loss of binding to target regulatory elements. ${ }^{28}$ Mutation of these three residues to alanine creates a constitutively active mutant (FoxO1-AAA), which cannot be phosphorylated by PI3k-Akt pathway and therefore remains in the nucleus.

In the current study, we showed that expression of Bim is mediated by FoxO1 and indirectly downregulated by $\mathrm{TH} / \mathrm{TR}$. $\mathrm{T}_{3} / \mathrm{TR}$ suppresses FoxO1 through transcriptional regulation and Akt-mediated nuclear exclusion and degradation. These events subsequently lead to chemotherapy resistance and doxorubicinpromoted metastasis of TR-expressing hepatoma cells.

\section{Results}

$\mathrm{T}_{3}$ regulates Bim mRNA and protein levels in TRoverexpressing hepatoma cells. To explore the tumorkilling mechanism of TRs in HCC, the expression patterns of apoptosis-related genes in TR-overexpressing hepatoma cells following $T_{3}$ treatment were examined via microarray. Among the range of apoptosis-related genes investigated, Bim was significantly downregulated upon $\mathrm{T}_{3}$ stimulation. To confirm this finding, ectopic expression of TR $a$ and $\operatorname{TR} \beta$ with adenovirus in $\mathrm{J} 7$ and Hep3B hepatoma cell lines was performed (Figure 1a). The levels of Bim mRNA were suppressed in a time-, dose- and TR-dependent manner in various TR-overexpressing $\mathrm{J} 7$ cells following $\mathrm{T}_{3}$ treatment (Figure 1b). The effect of $\mathrm{T}_{3}$ on Bim protein expression was additionally assessed in isogenic cell lines derived from $\mathrm{J} 7$ or Hep3B. After incubation with 0 or $10 \mathrm{nM} \mathrm{T}_{3}$, levels of the three isoforms ( $E L, L$ and $S$ ) of Bim protein were dramatically suppressed in TR-overexpressing but not control cells (Figures $1 \mathrm{c}$ and $\mathrm{d}$ ). Our results clearly indicate that $\mathrm{T}_{3}$ inhibits Bim expression at both the mRNA and protein level in a TR-dependent manner in hepatoma cells.

$\mathrm{T}_{3}$ /TR-dependent suppression of the Bim promoter is exerted via Fox01. To determine whether $\mathrm{T}_{3} / \mathrm{TR}$-mediated Bim downregulation occurs through transcriptional repression or other means, the human Bim promoter region encompassing nucleotides from upstream position -1995 to +338 (promoter region 1, P1) was cloned into pGL3-basic-TK vector, and regulation by TR was determined via measuring luciferase activity. Various deletion mutants from this region were additionally generated to pinpoint the crucial elements responsible for $\mathrm{T}_{3}$-induced Bim repression (promoter regions 15, P1-P5). Using these reporter constructs, the effects of transrepression of $\mathrm{TR} / \mathrm{T}_{3}$ on the Bim $5^{\prime}$-flanking regions were determined.

Following the reporter activity assay, luciferase activities of the reporters driven by fragments -1995 to $+338,-1000$ to +338 and -440 to +338 (P1-P3) were dramatically suppressed in the presence of $\mathrm{T}_{3}$ in J7-TR cells. Interestingly, the suppressive effect of $\mathrm{T}_{3}$ on both -190 to +338 (P4) and -1950 to +243 (P5) regions was partially relieved. Previous studies have identified two putative FoxO1-binding elements, F-box1 (positions - 216 to - 223) and F-box 2 (positions +276 to +283$)$, within this region that have critical roles in Bim activation. $^{22,23}$ We propose that these two F-boxes mediate the suppressive effect of $\mathrm{T}_{3}$ on the Bim promoter, in view of the finding that deletion of either one reduces the inhibitory effect of $\mathrm{T}_{3}$ (Figure 2b, P4 and P5). Site-directed mutagenesis of either F-box 1 (Figures 2a and b, P6) or F-box 2 (Figures 2a and $b, P 7)$ in the $\mathrm{P} 1$ promoter partially rescued $\mathrm{T}_{3}$-suppressed luciferase activity. Furthermore, mutation of both elements (P8) led to blockade of the inhibitory effect of $T_{3}$ (Figure 2a). These data clearly suggest that F-box 1 and F-box 2 are the major cis-elements mediating the repressive effect of $T_{3}$ on the Bim promoter.

To further establish whether $\mathrm{T}_{3}$-mediated transcriptional repression of Bim is FoxO1 dependent, we assessed the effect of FoxO1 on Bim promoter activity in $\mathrm{J} 7$ or J7-TR cells in the absence and presence of $\mathrm{T}_{3}$. Bim promoter-driven reporter assays showed that FoxO1 overexpression enhances Bim promoter activity in $\mathrm{J} 7$ cells (Figure $2 \mathrm{c}$ ). Additionally, ectopic overexpression of wild-type FoxO1 (FoxO1-wt) in J7-TR cells partially eliminated the effect of $\mathrm{T}_{3}$ on the Bim promoter (Figure 2c). Overexpression of FoxO1-AAA, a constitutively active form of FoxO1 (in which the three Akt phosphorylation sites are mutated to alanine) fully blocked the suppressive effect of $\mathrm{T}_{3}$ on the Bim promoter (Figure 2d). Our findings collectively demonstrate an important role of FoxO1 in $\mathrm{T}_{3}$-mediated regulation of Bim promoter activity and further suggest that $T_{3}$ suppresses Bim promoter activity by interfering with FoxO1-mediated activation of the Bim promoter via regulating Akt-mediated phosphorylation of FoxO1. 
a

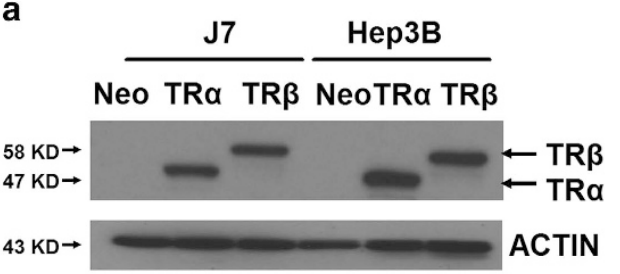

b
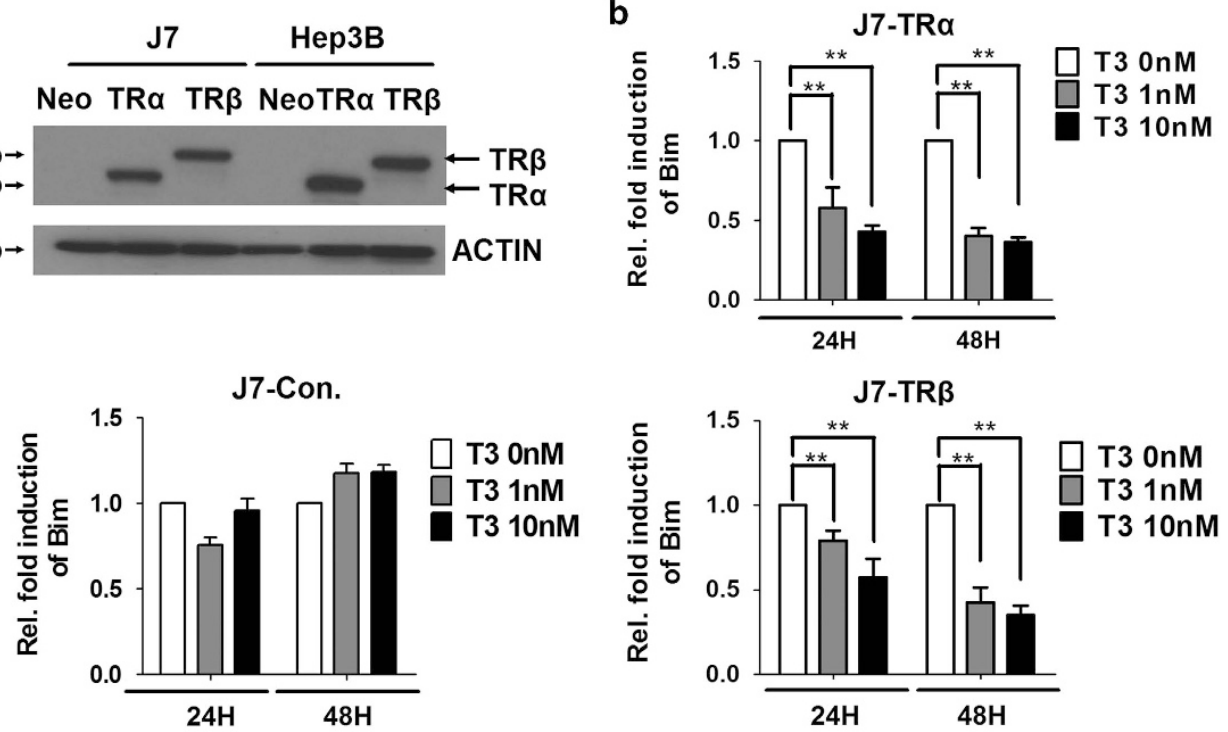

C

J7-Control
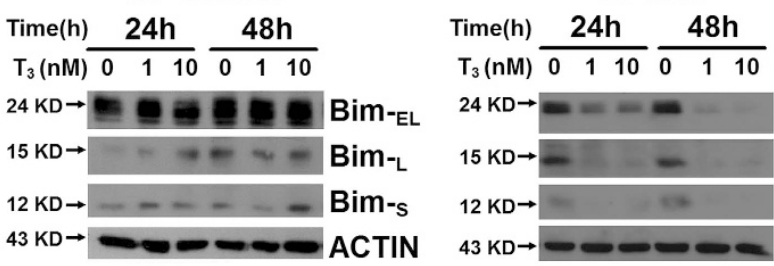

J7-TRa
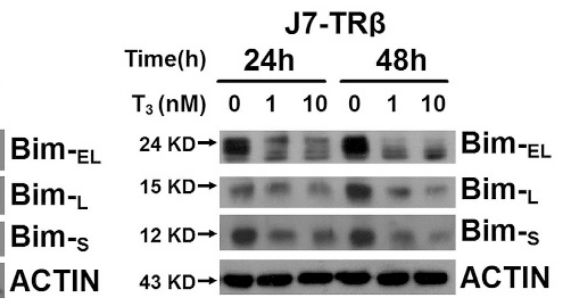

d

Hep3B-Control

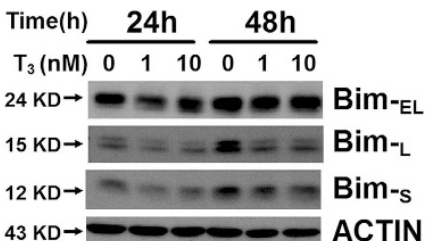

Hep3B-TR $\alpha$

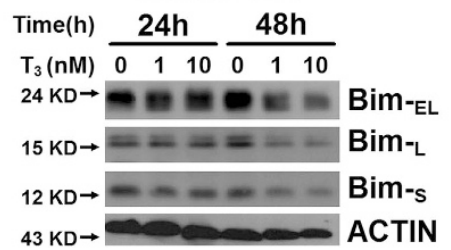

\section{Hep3B-TRß}

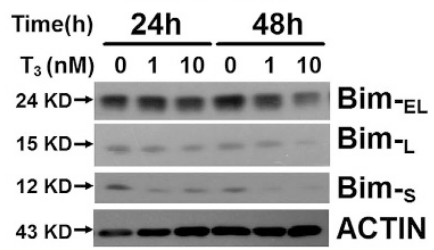

Figure 1 Effect of $\mathrm{T}_{3}$ on Bim mRNA and protein expression in hepatoma cell lines. (a) Detection of TR protein in TR-overexpressing or control J7 and Hep3B cell lines. (b) RNA from TR-overexpressing or control cell lines maintained in $\mathrm{T}_{3}$-depleted $\left(\left[\mathrm{T}_{3}\right]=0 \mathrm{nM}\right)$ or supplemented medium $\left(\left[\mathrm{T}_{3}\right]=1\right.$ or $\left.10 \mathrm{nM}\right)$ for 24 or $48 \mathrm{~h}$ was prepared prior to qRT-PCR analysis of Bim mRNA. Values (means \pm S.E.M.) are shown as fold induction relative to $0 \mathrm{nM} \mathrm{T}_{3}$. All assays were repeated at least three times. ${ }^{* *} P<0.01 ;{ }^{*} P<0.05$ (c and d) Levels of the three isoforms of Bim (Bim-EL, Bim-L and Bim-s) in total lysates of isogenic J7 and Hep3B cell lines maintained in the absence or presence of $\mathrm{T}_{3}$ ( 1 or $10 \mathrm{nM}$ ) for 24 or $48 \mathrm{~h}$ were determined via western blotting. ACTIN signals served as the loading control

$\mathrm{T}_{3} / \mathrm{TR}$ represses FoxO1 expression through genomic and non-genomic effects. Although a crucial role of FoxO1 in $\mathrm{T}_{3}$-mediated transcriptional repression of Bim has been demonstrated, the issue of whether the FoxO1 transcription factor is regulated by $T_{3} / T R$ is yet to be clarified. RNA levels of FoxO1 were dramatically repressed in $\mathrm{J} 7$ cells after incubation with $T_{3}$ in a time-, dose- and TR-dependent manner (Figure 3a). Similarly, the protein levels of FoxO1 were repressed by $\mathrm{T}_{3}$ in TR-expressing $\mathrm{J} 7$ and Hep3B cell lines (Figures $3 b$ and $c$ ). Notably, $T_{3}$ effect on the repression of FoxO1 and Bim proteins was observed in Huh7, a hepatoma cell line expressing endogenous TR proteins. (Supplementary Figures S1A and B). Regulation of Bim expression by FoxO1 was examined by GFP-FoxO1 overexpression transiently. Dramatic enhancement of all isoforms of Bim protein was observed (Figure $3 d$ ). To further ascertain whether the suppressive effect of $T_{3}$ on Bim protein occurs through FoxO1 downregulation, FoxO1-wt or FoxO1-AAA was overexpressed in J7-TR cells following $T_{3}$ treatment. Interestingly, FoxO1-wt had only a minor effect in restoring the Bim protein level in the presence of $T_{3}$. However, overexpression of FoxO1-AAA, diminished the $\mathrm{T}_{3}$-suppressive effect on Bim protein expression (Figure $3 e$ ). These data were consistent with the results of the reporter assays (Figure 2a) and suggest that $\mathrm{T}_{3}$ not only suppresses FoxO1 expression at the transcriptional level but also influences its activities via Akt-mediated nuclear exclusion or degradation. As $T_{3} / T R$ can trigger rapid, non-transcriptional effects through cross-coupling with the phosphatidylinositol 3-kinase (PI3K)Akt pathway, ${ }^{29}$ we explored whether $\mathrm{T}_{3}$ influences FoxO1 activity in hepatoma cells through a non-genomic mechanism. The level of activated phospho-Akt was dynamically 


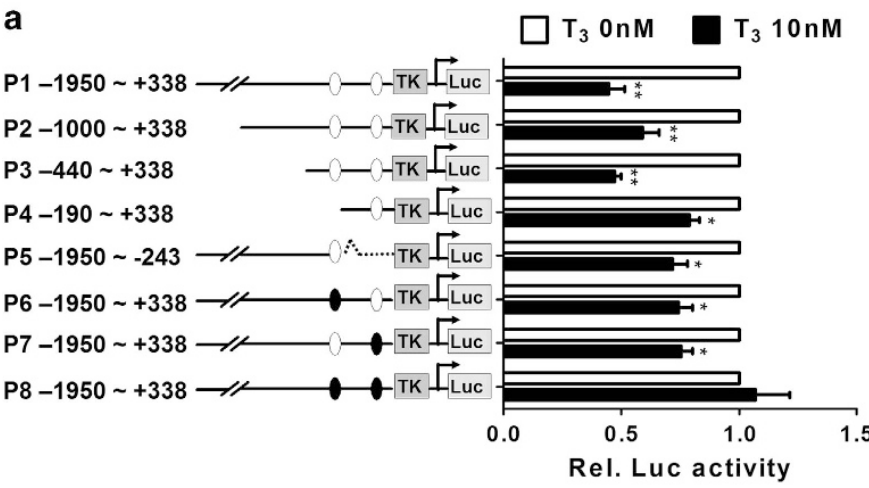

C

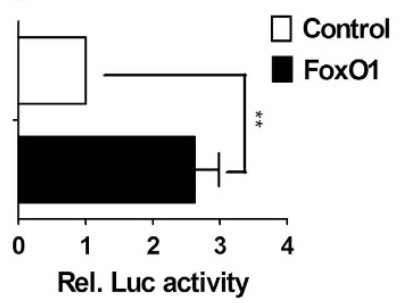

d

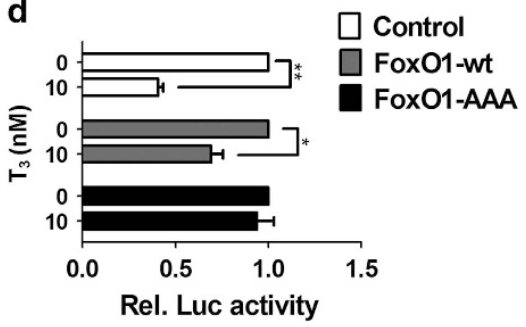

FoxO consensus binding sequence: GTAAACAA

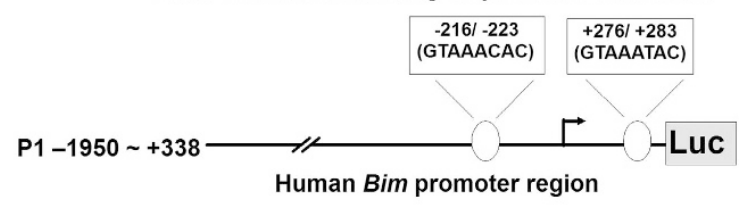

wt: GTAAACAC/ GTAAATAC

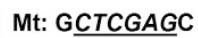

Figure $2 \mathrm{~T}_{3}$ /TR-dependent suppression of the Bim promoter via Fox01. (a) The Bim 5'-flanking region (-1950 to +338; P1), Bim 5'-deletion and FoxO1 consensus-binding site mutants (P1-P8) were cloned into pGL3-basic-TK vector to generate luciferase reporter plasmids. The promoter region in these mutants is shown (left). After co-transfection with $\beta$-galactosidase (a transfection efficiency control), J7-TR cells were harvested and luciferase activity was measured following treatment with $\mathrm{T}_{3}(0$ or $10 \mathrm{nM})$ for $48 \mathrm{~h}$. Luciferase activity was normalized to that of $\beta$-galactosidase $\left({ }^{\star *} P<0.01\right.$; $\left.{ }^{*} P<0.05\right)$. (b) The structure of the human Bim $5^{\prime}$-flanking region (positions -1950 to +338 ; P1) containing two putative FoxO1 consensus-binding sites. (c) Luciferase activities of the Bim promoter were analyzed in J7 cells after ectopic expression of control or FoxO1-wt via adenoviral transfection. Luciferase activity was normalized to that of $\beta$-galactosidase. Data represent means \pm S.E.M. of values derived from three independent experiments $\left({ }^{\star \star} P<0.01 ;{ }^{*} P<0.05\right)$. (d) Following ectopic expression of control, FoxO1-wt or FoxO1-AAA via adenoviral (Ad-control, -FoxO1-wt or -FoxO1-AAA) infection in J7-TR cells, the effects of $T_{3}$ on Bim promoter (positions -1950 to +338 ; P1) activity were examined as for panel (a)

enhanced (Figure 3f), in parallel with downregulation of Bim and the nuclear exclusion of endogenous FoxO1 or exogenous GFP-FoxO1 after $\mathrm{T}_{3}$ treatment (Supplementary Figure $\mathrm{S} 2$ and Figures $3 g$ and $h$ ). The results indicate that $\mathrm{T}_{3} / \mathrm{TR}$ represses FoxO1 through both genomic and nongenomic effects, leading to decreased Bim expression.

Bim acts synergistically with cisplatin, doxorubicin and tumor necrosis factor-related apoptosis-inducing ligand (TRAIL) to kill hepatoma cells. The expression levels of Bim proteins in several hepatoma cells with various invasion/ metastatic capabilities at distinct differentiation stages were compared. Bim proteins were highly enriched in Hep3B and Mahlavu but present at lower levels in HepG2 and SK-Hep1 cells (Figure 4a). To ascertain whether higher levels of Bim sensitize hepatoma cells to chemotherapeutic drugs or tumor-killing cytokines, Bim-s was overexpressed via adenoviral transduction in HepG2 and Sk-Hep1 cell lines displaying low Bim expression, followed by challenge with the anticancer drugs cisplatin, doxorubicin or recombinant (r)-TRAIL (Figure 4b). Cell viability results with both cell types indicated enhanced cisplatin, doxorubicin and r-TRAIL-induced cell death in Bim-s-overexpressing cells (Figure 4c). Moreover, although all the tested drugs triggered apoptotic events, as evident from increased activation of Caspase- 3 and the number of cells in the sub-G1 populations, their effects were significantly enhanced upon Bim overexpression in HepG2 and Sk-Hep1 cells (Figures $4 d$ and e). To further determine the influence of Bim on anticancer drug-mediated apoptosis of hepatoma cells, expression in $\mathrm{J} 7$, the hepatoma cell line containing physiologically high levels of Bim, was reduced using the shRNA-mediated knockdown approach (Figure 4f). As expected, the extent of cisplatin, doxorubicin or r-TRAILinduced apoptosis (indicated by cell viability and active caspase 3 levels) was dramatically reduced in Bim-depleted $\mathrm{J} 7$ cells (Figures $4 \mathrm{~g}-\mathrm{i}$ ). These results suggest that Bim acts as a synergistic factor to induce apoptosis in hepatoma cells challenged with chemotherapeutic drugs or tumor-killing cytokines, such as TRAIL.

$\mathrm{T}_{3}$-mediated Bim downregulation protects hepatoma cells against cisplatin, doxorubicin and TRAIL-induced apoptosis. To further clarify the influence of $T_{3} / T R$ on activities of anticancer drugs, TR-overexpressing J7 cells and Huh7 cells were stimulated with several chemotherapeutic drugs and r-TRAIL. The apoptotic events following addition of cisplatin, doxorubicin and r-TRAIL were significantly reduced in $\mathrm{T}_{3}$-pretreated J7-TR and Huh7 cells (Figures $5 \mathrm{a}-\mathrm{C}$ and Supplementary Figure S3). We were interested in clarifying whether $\mathrm{T}_{3}$ influences the sensitivity of hepatoma cells to these drugs via downregulation of Bim. To this end, Bim-s was ectopically expressed in J7-TR and Huh7 cells with or without $\mathrm{T}_{3}$ treatment (Figure $5 \mathrm{~d}$ and Supplementary Figure S4A). Interestingly, although $\mathrm{T}_{3}$ pretreatment protected J7-TR and Huh7 cells control cells from apoptosis induced by chemotherapeutic agents, the 

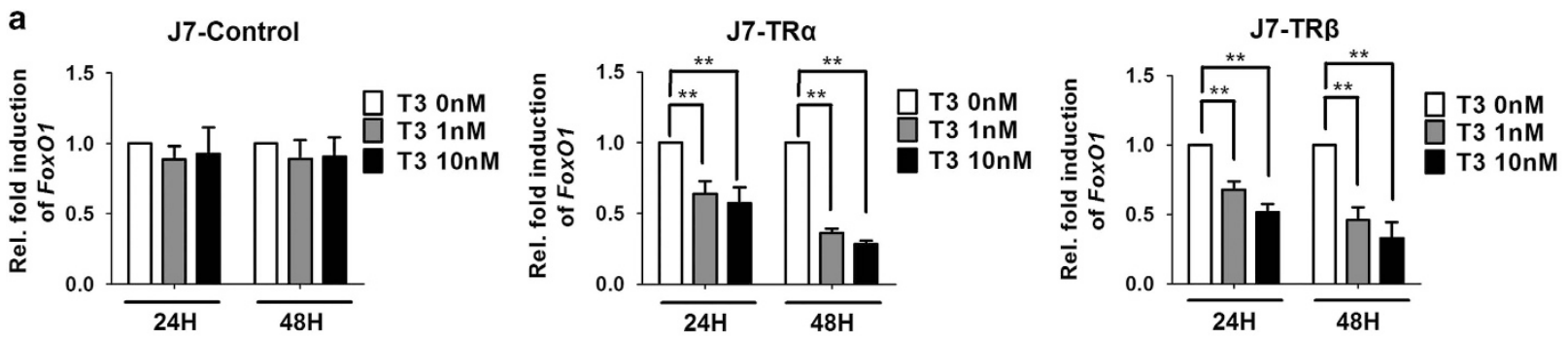

b
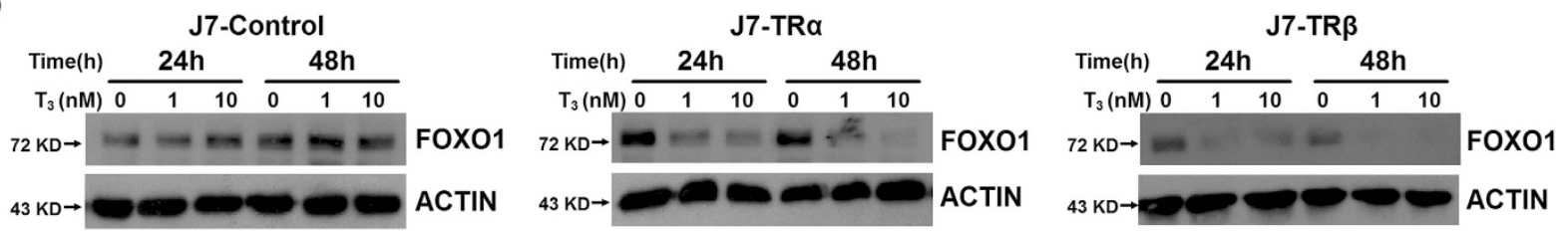

C

Hep3B-Control
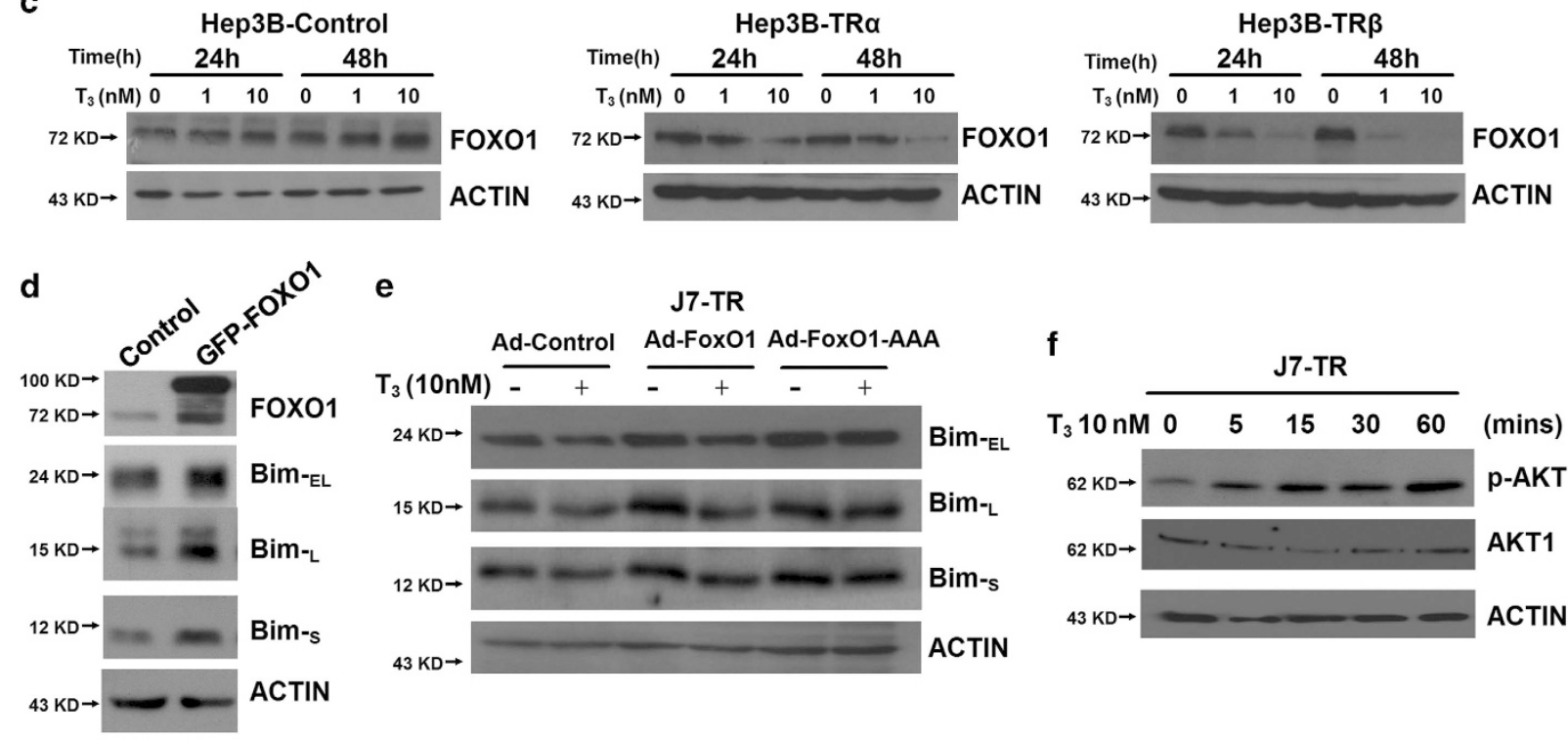

e

J7-TR

Ad-Control Ad-Fox01 Ad-Fox01-AAA $\mathrm{T}_{3}(10 \mathrm{nM}) \overline{\mathrm{t}}+\frac{}{-+}+$

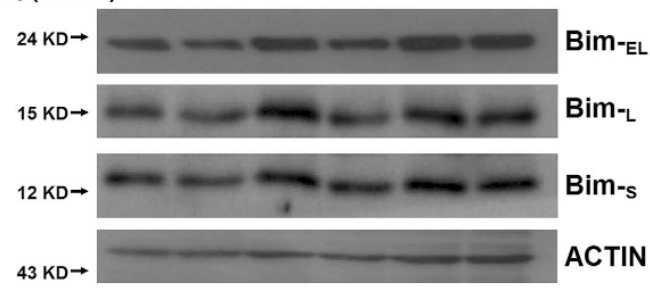

f

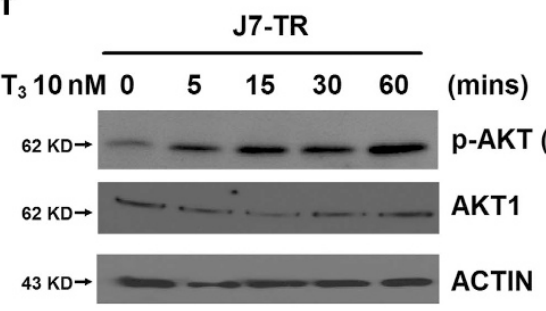

g

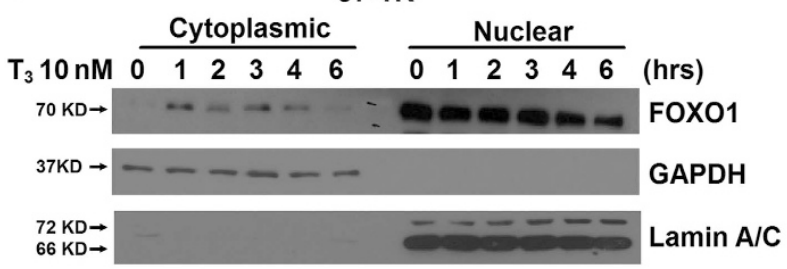

h

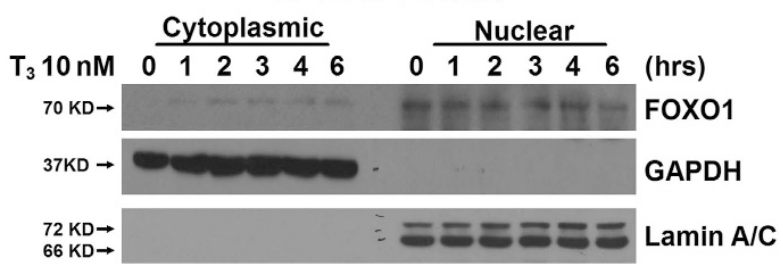

Figure $3 \mathrm{~T}_{3} / \mathrm{TR}$ represses Bim protein expression via downregulation of FoxO1. (a) RNA from TR-overexpressing or control $\mathrm{J} 7$ cells in the absence or presence of $\mathrm{T}_{3}$ for 24 or $48 \mathrm{~h}$ was prepared prior to qRT-PCR analysis of Fox01 mRNA expression. Values (means \pm S.E.M.) are shown as fold induction, compared with $0 \mathrm{nM} \mathrm{T}$. All assays were repeated at least three times ( ${ }^{* *} P<0.01$ ). (b and $\left.\mathbf{c}\right)$ FoxO1 protein levels in total lysates of isogenic $\mathrm{J} 7$ and Hep3B cell lines maintained in the absence or presence of $\mathrm{T}_{3}(1$ or $10 \mathrm{nM}$ ) for 24 or $48 \mathrm{~h}$, determined using western blotting. ACTIN signals served as the loading control. (d) After transfection of GFP-FoxO1 for $48 \mathrm{~h}$ in J7 cells, the expression levels of FoxO1 and three isoforms of Bim were examined using western blotting. (e) Following ectopic expression of control, FoxO1-wt or FoxO1-AAA via adenoviral infection in J7-TR cells, the effects of $T_{3}$ on Bim protein expression were examined using western blotting. (f) Following $T_{3}(10 \mathrm{nM})$ stimulation for the indicated times, lysates of J7-TR cells were extracted for examining phosphor-AKT expression with western blotting. AKT1 and ACTIN were used as internal controls. $(\mathbf{g}$ and $\mathbf{h})$ After $\mathrm{T}_{3}$ (10 nM) treatment for the indicated times, cytoplasmic and nuclear fractions of J7-TR or GFP-Fox01-overexpressing J7-TR cells were extracted for detecting endogenous Fox01 or exogenous GFPFox01 protein expression

antiapoptotic effect of $\mathrm{T}_{3}$ was abolished in Bim-overexpressing cells (Figures $5 \mathrm{e}-\mathrm{g}$ and Supplementary Figures $4 \mathrm{~B}-\mathrm{D}$ ). The protective effect of $T_{3} / T R$ against drug-induced cell death was further studied in vivo using subcutaneous xenografts of control (J7-Neo) and TR-overexpressing J7 cells (J7-TR) in euthyroid nude mice. Concordant with in vitro results, TR overexpression conferred not only tumor growth advantage but also resistance to cisplatin and doxorubicin in $\mathrm{J} 7$ 
hepatoma cells (Figure 5h). Based on these collective findings, we propose that $T_{3} / T R$ inhibits the apoptotic effects of chemotherapeutic drugs in hepatoma cells through suppressing expression of the apoptosis regulator FoxO1 and its downstream target Bim.
Bim suppresses TH/TR-enhanced doxorubicin resistance and metastasis. Several lines of evidence suggest that chemotherapeutic drugs alternatively have the potential to accelerate tumor progression of apoptosis-resistant cells. $^{30}$ To further explore this issue, a transwell assay was a

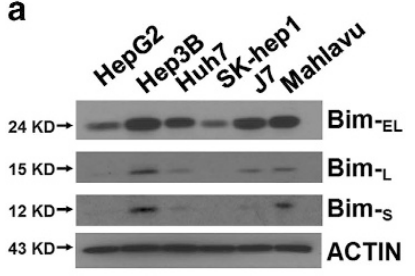

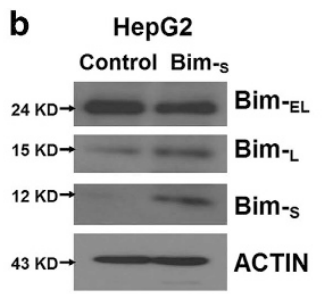

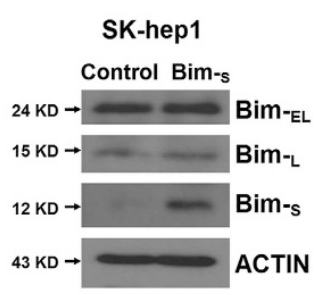

Ad-Control Ad-Bim

Cisplatin - + - +

Doxorubicin - -+-+

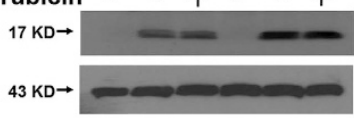

HepG2

Ad-Control Ad-Bim

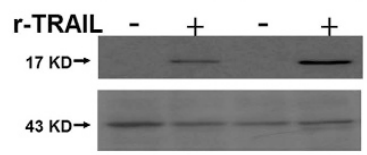

e

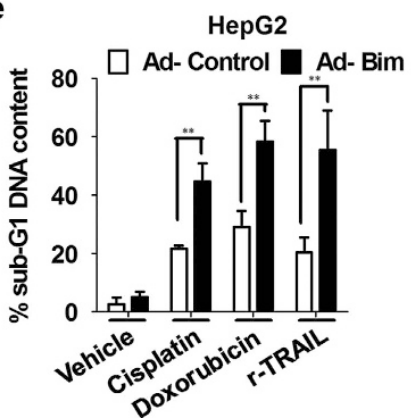

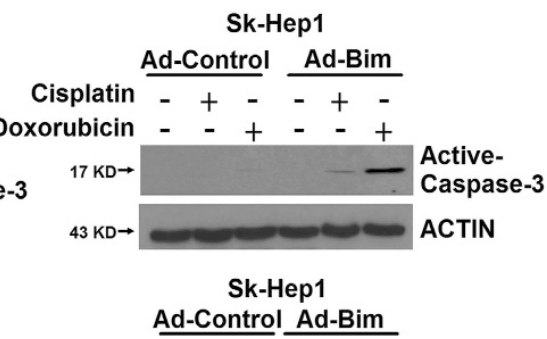

Sk-Hep1

Ad-Control Ad-Bim

Cisplatin $-+-\overline{-}+$

Active-

Caspase-3

ACTIN

Sk-Hep1

Ad-Control Ad-Bim

Active-

Caspase-3

ACTIN

Active-

Caspase-3

ACTIN f

Sk-Hep1

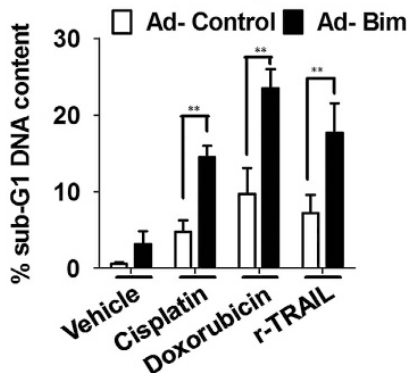

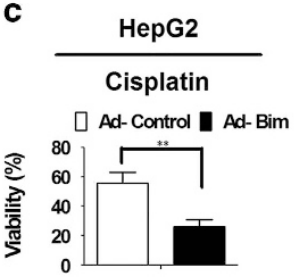

Doxorubicin

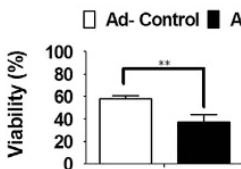

r-TRAIL

口 Ad-Control \ Ad-Bim

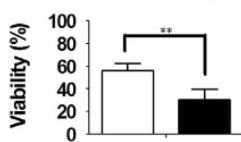

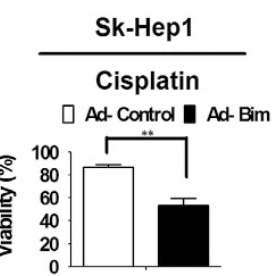

Doxorubicin

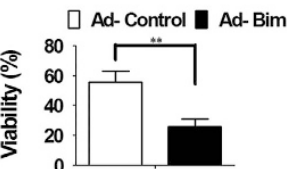

r-TRAIL

C Ad-Control I Ad-Bim

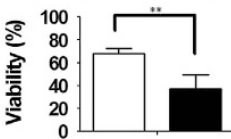

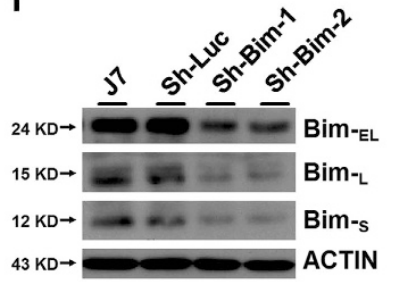

g Cisplatin

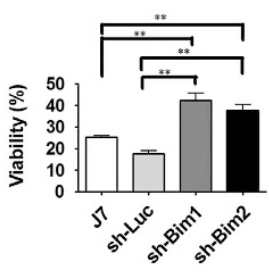

Doxorubicin

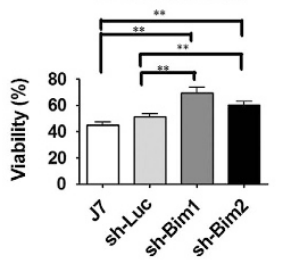

r-TRAIL

h
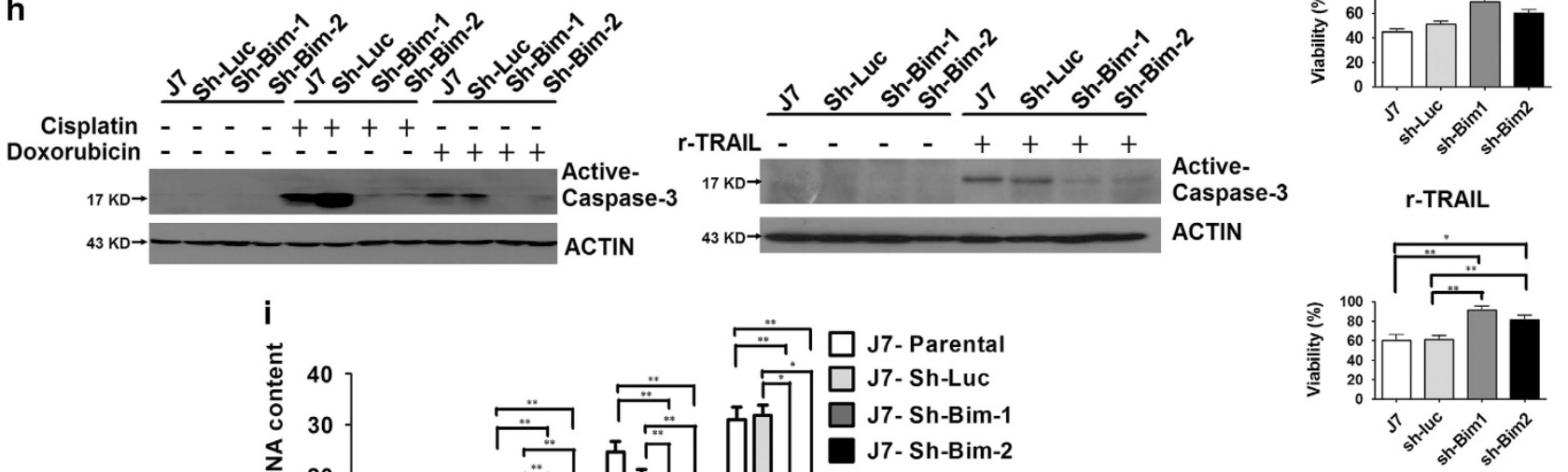
employed to determine the metastatic capabilities of $\mathrm{T}_{3}$-treated J7-TR cells in the presence of cisplatin or doxorubicin. cisplatin treatment dramatically inhibited cellular migration and invasion, regardless of $\mathrm{T}_{3}$ (Figures $6 \mathrm{a}$ and $\mathrm{b}$ ). Interestingly, doxorubicin suppressed cellular migration but enhanced the invasive potential of J7-TR cells. Additionally, $\mathrm{T}_{3}$ treatment further accelerated doxorubicin-mediated cellular invasion (Figure $6 \mathrm{~b}$ ). The results imply that $\mathrm{T}_{3}$ stimulates apoptosis resistance of J7-TR cells and, subsequently, doxorubicin-enhanced invasion. To ascertain whether Bim has the ability to eliminate the effects of $T_{3}$ and doxorubicin on cellular invasion, ectopic expression of Bim in J7-TR and Huh7 cells was achieved, followed by transwell invasion analysis. Notably, Bim expression led to dramatic suppression of the invasive ability of J7-TR and Huh7 cells, even in the presence of doxorubicin and $T_{3}$ (Figure $6 \mathrm{c}$ and Supplementary Figure S5). To further ascertain whether these $\mathrm{T}_{3} / \mathrm{TR}$-associated effects are replicated in vivo, the orthotopic mouse model was employed. Tumor growth and metastasis were monitored with in vivo imaging system (IVIS) weekly after liver implantation of Luc-GFP-expressing J7-Neo or J7-TR tumors. Concordant with the in vitro results, TR overexpression not only caused tumor resistance to doxorubicin but also increased the metastatic potential of $\mathrm{J} 7$ hepatoma cells in vivo (Figure 6d). Taken together, these observations confirm that $\mathrm{T}_{3} / \mathrm{TR}$ inhibits the apoptotic effects of doxorubicin through Bim downregulation, subsequently promoting tumor progression.

\section{Discussion}

HCC is the fifth most common cancer and the third most common cause of cancer-related mortality worldwide. More than 748000 newly diagnosed cases and about 700000 deaths occur annually. ${ }^{7,31}$ Because of the advanced stage of this disease at the time of diagnosis, $<30-40 \%$ of HCC cases are eligible for curative treatments, including surgery, liver transplantation or percutaneous ablation. ${ }^{32}$ Eventually, the majority of HCC patients require chemotherapy. To date, doxorubicin has been widely used as a chemotherapeutic drug for advanced HCC but displays low efficacy with a $\sim 15-20 \%$ response rate. ${ }^{32}$ Other chemotherapeutic agents, such as cisplatin, Etoposide, 5-Fluorouracil and their combinations, demonstrate even lower efficacy. ${ }^{33}$ Because of the poor response to the currently available chemotherapeutic agents, continuous efforts have been made to establish new molecular targets or signaling pathways for developing more effective drugs.
Circulating $\mathrm{TH}$ and its cognate receptors have pivotal roles in controlling cellular development and metabolic homeostasis in vertebrates. Additionally, it is increasingly apparent that TH/TRs have important roles in HCC development, with several documented roles in tumorigenesis. For instance, expression levels of TRs and their target genes are decreased in early preneoplastic lesions and hepatocellular HCC in rats, and local hypothyroid status may favor the onset and progression of preneoplastic lesions to $\mathrm{HCC} .{ }^{34}$ A recent epidemiological study also suggested that long-term hypothyroidism is positively correlated with HCC incidence, independent of other risk factors. ${ }^{35}$ However, the proposed tumor-suppressor role of TRs remains a subject of controversy. For example, an animal model of colorectal tumorigenesis revealed that TRa1 positively regulates several molecules downstream of the Wnt signal, consequently facilitating the expression of $\beta$-catenin/Tcf 4 target genes and enhancing cell growth. Intriguingly, in a strain of Wntactivated $\mathrm{Apc}^{+} /{ }^{1638 \mathrm{~N}}$ mice, TRa overexpression in the intestinal epithelium did not induce cancer formation but rather accelerated tumorigenesis. ${ }^{36}$ Recently, another group reported that TRs act as potent suppressors of tumor metastasis in breast cancer cell lines. ${ }^{37}$ The investigators further showed that mice with double knockout of $T R a$ and $T R \beta$ are vulnerable to epithelial tumors and that TR deficiency suppresses the number of benign tumors but enhances malignant tumor formation during carcinogenesis. Thus TH/TR appears to perform dual roles, mitogenic and tumor suppressive, in various tissues, although the mechanisms by which these two functions are coupled remain to be elucidated.

Adult liver is a quiescent organ that exhibits an extremely low mitosis frequency ( $<1 / 20000$ hepatocytes). However, several lines of evidence suggest that liver damage caused by partial hepatectomy or other means (including chemical-, nutrition-, vascular- or viral-mediated liver injury) strongly enhances the hepatocyte turnover rate to regenerate damaged parts. These stimulated hepatocytes have higher potential to generate tumor precursor cells that later develop into preneoplastic lesions or HCC. ${ }^{38-40}$ Previous studies using the DEN-induced HCC animal model have suggested that $\mathrm{T}_{3}$ serves as a hepatomitogenic factor to stimulate liver cell growth but without associated cell death, consequently leading to decreased preneoplastic hepatic lesions. ${ }^{10,11}$ However, in advanced HCC cells, the TH may exert a pro-survival function, causing chemotherapeutic drug resistance. The mitogenic effect of $\mathrm{TH}$ may promote malignant hepatic tumor progression or chemoresistance but requires further investigation. In the current study, we confirmed the protective role of $T_{3} / T R$ in hepatoma cells following challenge with several chemotherapeutic agents. Our data

Figure 4 Bim acts synergistically with cisplatin, doxorubicin and TRAlL to kill hepatoma cells. Detection of Bim proteins in (a) parental HCC cell lines and (b) Ad-Bim-infected HepG2 or SK-hep1 cells. (c) Ad-control or Ad-Bim infected cells were treated with cisplatin $(2.5 \mu \mathrm{g} / \mathrm{ml})$, doxorubicin $(2.5 \mu \mathrm{M})$ or r-TRAll $(10 \mathrm{ng} / \mathrm{ml})$ for $48 \mathrm{~h}$. After stimulation, cell viability was measured using the MTT assay, and data are presented as relative absorbance values (\%) of vehicle-treated cells. (d and e) Control and Bim-overexpressing cells were treated with the indicated reagents for $24 \mathrm{~h}$, the extent of caspase-3 activation determined via western blotting (d), and the proportions of apoptotic cells in samples subjected to various treatments assessed using propidium iodide (PI) staining and flow cytometry (e). Values are presented as means \pm S.E.M. of data from experiments performed in triplicate. Differences between data were evaluated using Student's $t$-test $\left({ }^{\star *} P<0.01 ;{ }^{*} P<0.05\right)$. (f) Immunoblot analysis of the expression patterns of Bim proteins in $\mathrm{J} 7$ cells infected with lentivirus expressing luciferase (Sh-Luc) or Bim-targeting shRNA. (g) Control (Sh-Luc) or Bim-depleted (Sh-Bim) cells were treated with cisplatin $(2.5 \mu \mathrm{g} / \mathrm{ml})$, doxorubicin $(2.5 \mu \mathrm{M})$ or r-TRAlL $(10 \mathrm{ng} / \mathrm{ml})$ for $48 \mathrm{~h}$, and cell viabilities were determined via the MTT assay. The extent of caspase-3 activation and proportion of apoptotic cells were determined via (h) western blotting and (i) flow cytometry, respectively, and cell viability was measured using the MTT assay. (h) After treatment with the indicated reagents for $24 \mathrm{~h}$, caspase-3 activation in control or Bim-depleted cells was determined via western blotting analysis. (i) PI staining and flow cytometry were performed to assess the proportion of the sub-G1 phase in samples subjected to various treatments 
suggest that this function is attributable to downregulation of FoxO1 through both transcriptional repression and Aktmediated nuclear exclusion, subsequently leading to transcriptional repression of Bim.

The FoxO transcription factors are important regulators of cell cycle arrest and apoptosis acting downstream of PTEN. ${ }^{41}$ These proteins act as important tumor suppressors as they induce cell cycle arrest at the G1-S checkpoint through activation of $p 27^{-i p 1}$ or the G2-M checkpoint via activation of GAD45 to stimulate the DNA repair pathway. ${ }^{41-43}$ Furthermore, under sustained stress conditions, FoxOs induce expression of the pro-apoptosis gene, Bim, to trigger programmed death of overstressed/damaged cells. ${ }^{22,23}$ The ability of FoxO proteins to induce cell arrest and death at multiple steps has attracted considerable research efforts to assess their roles in carcinogenesis or as targets in cancer therapy. A number of lines of evidence have shown that Bim is the major mediator of the cell death effect of various anticancer drugs, including cisplatin and doxorubicin, and its degradation/downregulation is responsible for resistance to these drugs. Therefore, induction of Bim by

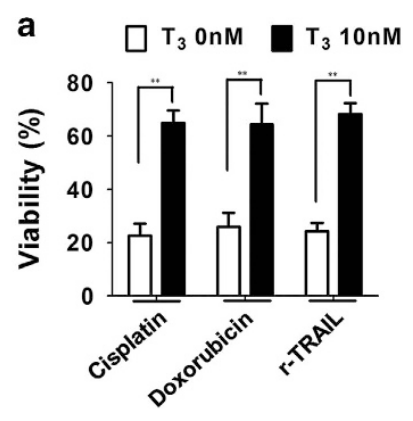

b

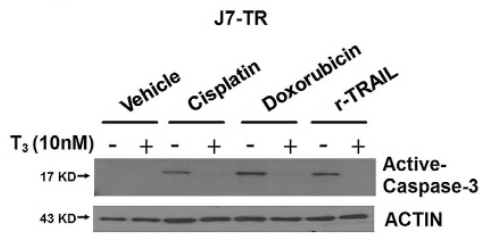

C

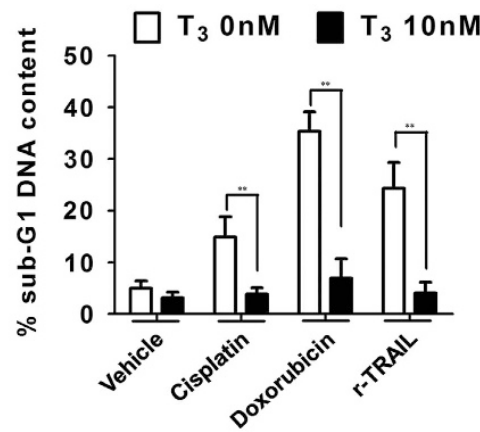

d

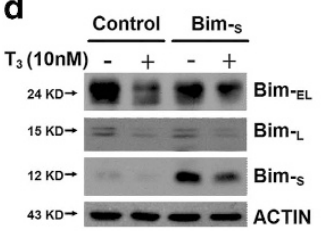

e

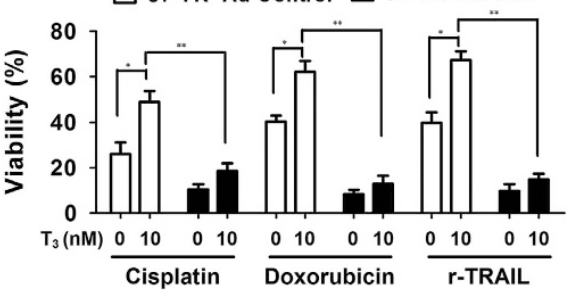

f<smiles>[R]=[In]C</smiles>

g

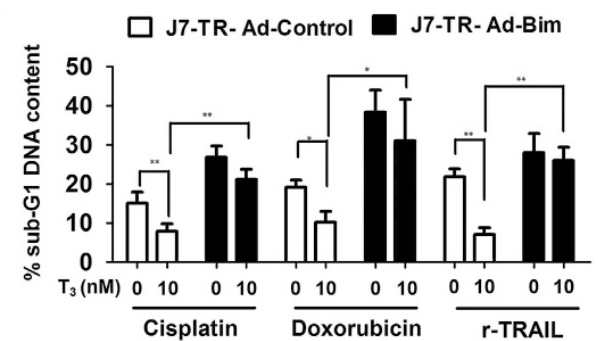

h

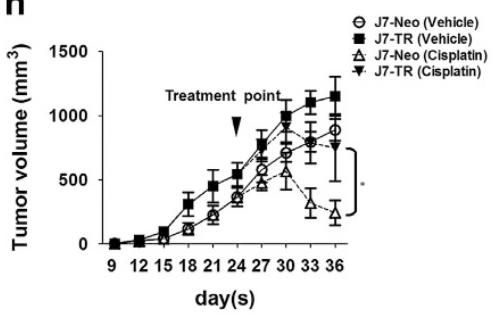

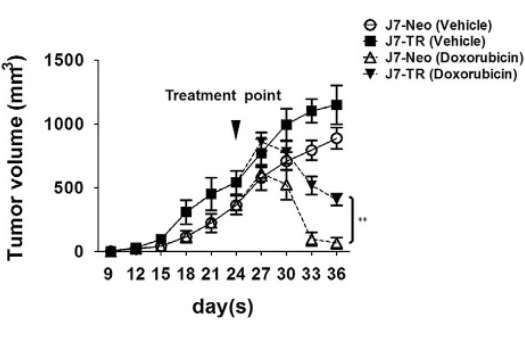

Figure 5 T $T_{3}$ TRR-induced cisplatin, doxorubicin and TRAIL resistance is mediated via Bim downregulation. (a) J7-TR cells were treated with the indicated reagents for $24 \mathrm{~h}$ after $\mathrm{T}_{3}(0$ or $10 \mathrm{nM})$ stimulation for $48 \mathrm{~h}$, and cell viability was measured using the MTT assay. Data are presented as relative absorbance values (\%) of vehicle-treated cells. The extent of caspase-3 activation and proportion of apoptotic cells were determined via (b) western blotting and (c) flow cytometry, respectively. (d) Bim-s was ectopically overexpressed in J7-TR cells via adenovirus infection in the presence or absence of $T_{3}$ for $48 \mathrm{~h}$, and Bim proteins were determined via western blotting. Cells were subsequently stimulated with the indicated agents for $24 \mathrm{~h}$. (e) Cell viabilities were determined with the MTT assay. ( $\mathbf{f}$ and $\mathbf{g}$ ) Caspase-3 activation was determined via western blotting and the percentage of apoptotic cells was assessed with PI-stained flow cytometry. (h) J7-Neo and J7-TR cells were subcutaneously injected into the flanks of nude mice. At 24 days after tumor inoculation, mice were treated with vehicle, cisplatin or doxorubicin. Tumor volumes were measured once every 3 days, and tumor growth curves are shown. Differences between data were evaluated using Student's $t$-test $\left({ }^{\star \star} P<0.01 ;{ }^{*} P<0.05\right)$

Figure 6 Bim suppresses TH/TR-enhanced doxorubicin resistance and metastasis. (a) In the presence of cisplatin $(2.5 \mu \mathrm{g} / \mathrm{ml})$ and doxorubicin (2.5 $\mu \mathrm{M})$, the migratory and (b) invasive properties of J7-TR cells treated with or without $T_{3}$ were assessed using the transwell assay. Images of traversing cells are shown in the left panels and the quantitative results in the right panels. To assess the influence of Bim on chemotherapeutic drugs-mediated invasion of J7-TR cells, (c) invasive properties of control or Bimoverexpressing J7-TR cells were stimulated with cisplatin or doxorubicin in the absence or presence of $T_{3}$ and subsequently assessed using the transwell assay. Images of traversing cells are shown in the upper panels and the quantitative results in the lower panels. Differences between data were evaluated using Student's $t$-test $\left({ }^{* *} P<0.01\right.$; ${ }^{\star} P<0.05$ ). (d) Tumors dissected from mice were subjected to subcutaneous injection with Luc-GFP-expressing J7-Neo and J7-TR cells were introduced orthotopically into the livers of nude mice and monitored weekly with IVIS. After 4 weeks, mice were treated with vehicle or doxorubicin (10 mg/kg, once a week). Relative intensity of luminescence from IVIS is shown in the upper panel, and representative IVIS images 13 weeks after tumor inoculation are shown in the lower panels 
a

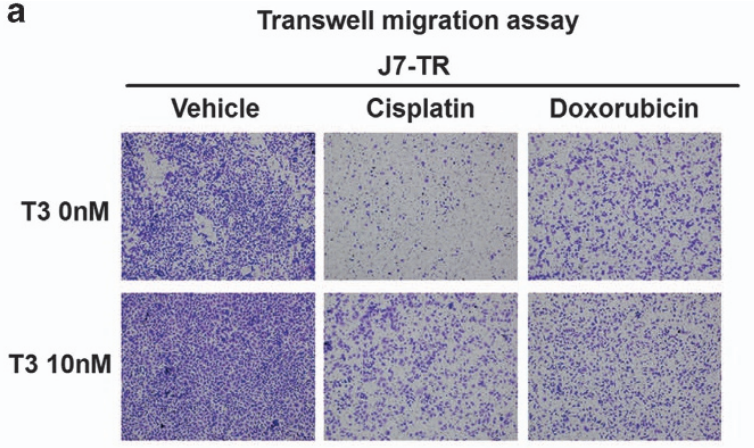

b

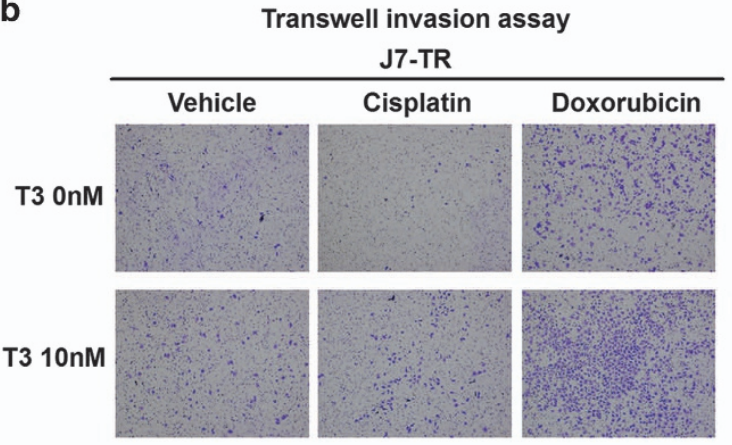

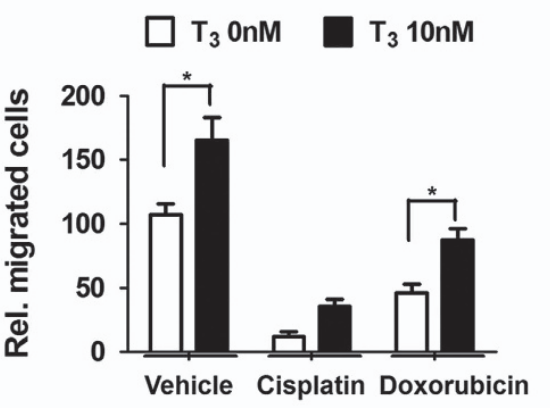

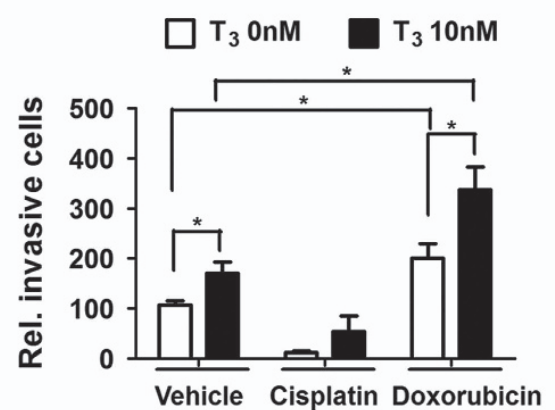

c
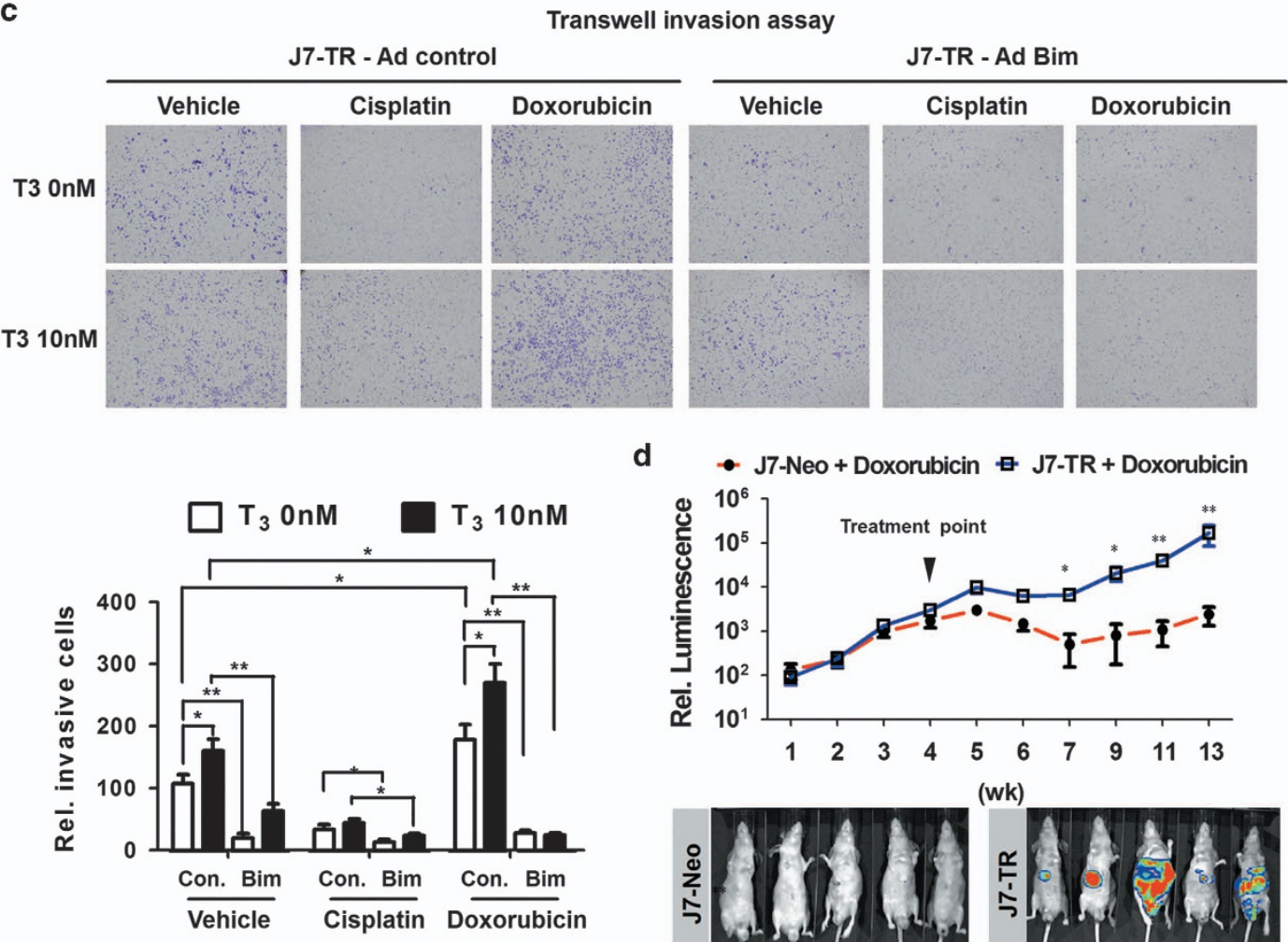

d
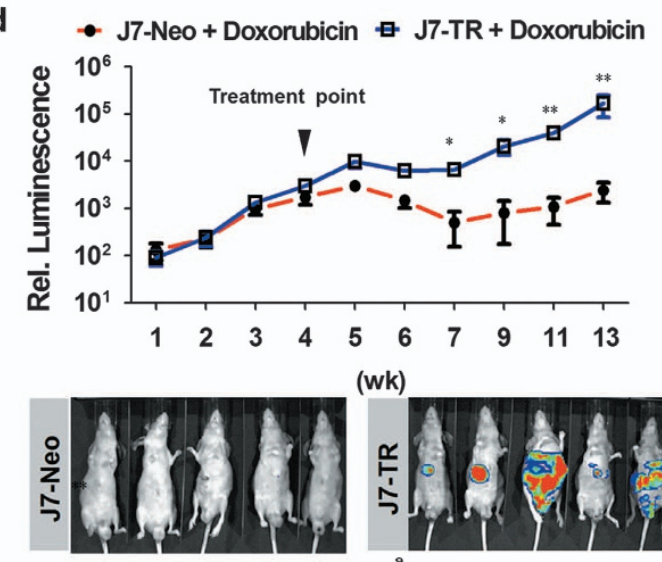

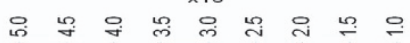


FoxO may have a key role in maintaining the Bim level in cancer cells and dictating their response to drugs. The current discovery that $\mathrm{T}_{3} / \mathrm{TR}$ can mitigate the FoxO/Bim cascade in HCC cells suggests that the TR expression level has a significant effect on patient responses to therapeutic drugs. Thus manipulating the $T_{3} / T R$ level in patients may become an important issue in cancer therapy.

Acquisition of anchorage independence is a crucial step for tumor metastasis. Cell life is dependent on anchorage, and cells undergo apoptosis after loss of attachment to ECM or adherence with their neighboring cells. Thus apoptosis induced by cell detachment, designated anoikis, is a critical barrier against tumor metastasis. Bim has a key role in anoikis in several cancer types, including breast cancer, lung cancer, osteosarcoma and melanoma. ${ }^{44-46}$ In these cancer types, abrogation of Bim-mediated cell death is required for metastasis. Our data indicate that doxorubicin has the potential to induce hepatoma cell invasion. Notably, $\mathrm{T}_{3}$-induced Bim repression not only caused chemotherapeutic drug resistance but also enhanced doxorubicin-induced metastasis of hepatoma cells. Conversely, ectopic expression of Bim in hepatoma cells strongly increased sensitivity to chemotherapeutic drugs and suppressed doxorubicin-induced metastasis, consequently abolishing TH/TR-enhanced apoptosis resistance and metastasis following drug treatment. The clinical relevance of the TH/TR-suppressed FoxO/Bim cascade needs to be further investigated to establish whether patients with abnormal levels (high or low) of TR show different degrees of metastasis.

Doxorubicin is one of the most commonly used chemotherapeutic drugs. However, several lines of evidence, including data from the current study, support its potential to accelerate malignant tumor progression, with a number of mechanisms proposed to explain this phenomenon. For instance, doxorubicin induces epithelial-mesenchymal transition and cell migration through TGF $\beta$ signaling activation in breast cancer. $^{30}$ MMP-2 and -9 , the crucial enzymes that degrade the ECM to facilitate tumor invasion, are activated by doxorubicin. ${ }^{47}$ Although the current findings suggest that suppression of Bim expression accounts to a large extent for TH/TR-enhanced doxorubicin-mediated metastasis, further studies are essential to ascertain whether metastasis is also enhanced via the above mechanisms. Our observations provide conclusive molecular evidence supporting targeting of the $\mathrm{TH}$ and Bim in chemotherapy regimens for $\mathrm{HCC}$.

\section{Materials and Methods \\ Cell culture. Hepatoma cell lines, including HepG2, Sk-Hep1, Hep3B and isogenic J7, were routinely cultured in Dulbecco's Modified Eagle's Medium (DMEM) supplemented with $10 \% \mathrm{FBS}(\mathrm{v} / \mathrm{v})$ at $37^{\circ} \mathrm{C}$ in a humidified atmosphere containing $5 \%(\mathrm{v} / \mathrm{V}) \mathrm{CO}_{2}$ and $95 \%(\mathrm{v} / \mathrm{V})$ air. $\mathrm{T}_{3}$-depleted $\left(\mathrm{T}_{3}, 0 \mathrm{nM}\right)$ serum was prepared by treatment with AG 1-X8 resin (Bio-Rad, Hercules, CA, USA) and added to DMEM at $10 \%(\mathrm{~V} / \mathrm{V})$ to form $\mathrm{Td}$ medium. $\mathrm{T}_{3}$ was purchased from Sigma-Aldrich (St. Louis, MO, USA).}

Real-time PCR (qRT-PCR). Total RNA of hepatoma cells was extracted using TRIzol reagent (Life Technologies Inc., Carlsbad, CA, USA), and cDNA strands were synthesized using the Superscript III Kit for RT-PCR (Life Technologies). Real-time quantitative RT-PCR was performed using SYBR Green reaction mix (Applied Biosystems, Carlsbad, CA, USA), and products detected using the ABI PRISM 7500 system (Applied Biosystems, Foster City, CA, USA).
Western blotting. Cell extracts were fractionated via SDS-PAGE on a $12 \%$ gel, and the separated proteins were transferred to a polyvinylidene fluoride membrane. Subsequent procedures were performed as described previously. ${ }^{48}$ Rabbit antihuman antibodies against Bim and active caspase-3 were purchased from Epitomics (Burlingame, CA, USA). The rabbit anti-GFP antibody was obtained from GeneTex (Irvine, CA, USA). Rabbit antibodies against FoxO1 were acquired from Cell Signaling Technology (Boston, MA, USA).

Transient transfection and reporter assays. The $5^{\prime}$-flanking region (positions -1950 to +338 ) of the Bim gene was amplified and cloned into pGL3-TK vector to generate a P1 reporter plasmid. Sequential 5'or $3^{\prime}$-deletions (P2-P5) and mutants of the Fox01 consensus-binding element (P6-P8) derived from this reporter were generated. To explore Bim promoter response to $\mathrm{T}_{3}$ or FoxO1 stimulation, J7-TR, J7-Fox01-WT or J7-FoxO1-AAA cells were transfected with $0.2 \mu \mathrm{g}$ of Bim promoter-driven reporter constructs and $0.05 \mu \mathrm{g}$ of SV $\beta$ vector expressing $\beta$-galactosidase (Clontech, Palo Alto, CA, USA) for $16 \mathrm{~h}$. Cells were subsequently treated with $\mathrm{T}_{3}(0$ or $10 \mathrm{nM})$ and incubated for $48 \mathrm{~h}$ prior to harvesting. Activities of luciferase and $\beta$-galactosidase were subsequently measured.

In vitro invasion assay. The influence of Bim on doxorubicin or $T_{3} / T R$ mediated invasive activity of TR-overexpressing hepatoma cell lines was assessed using the rapid Transwell in vitro assay. After adjusting cell density to $1 \times 10^{5}$ cells/ $100 \mu \mathrm{l}$ of serum-free DMEM, cells were added to each upper chamber coated with Matrigel (Becton-Dickinson, Franklin Lakes, NJ, USA). The lower chamber contained DMEM supplemented with $20 \%$ (v/v) FBS. Following incubation for $16 \mathrm{~h}$ at $37^{\circ} \mathrm{C}$, cells traversing the filter to the lower chamber were stained with crystal violet and counted. All assays were repeated at least three times. Amongtreatment differences were explored using one-way ANOVA $\left({ }^{*} P<0.05 ;{ }^{* *} P<0.01\right)$.

Xenograft mouse model. J7-Neo and J7-TR cells $\left(1 \times 10^{6}\right)$ were subcutaneously injected into the flanks of nude mice (BALB/CAnN.Cg-Foxn $1^{\text {nu/ }}$ CrINarl). At 24 days after tumor inoculation, mice were treated with vehicle, cisplatin ( $10 \mathrm{mg} / \mathrm{kg}$ once every 3 days, i.p) or doxorubicin ( $10 \mathrm{mg} / \mathrm{kg}$ once every 3 days, i.p). Tumor volumes were measured twice a week ( $n=4$ for each group), and tumor growth curves are shown.

Orthotopic mouse model. Tissues of subcutaneously grown Luc-GFPexpressing J7-Neo and J7-TR hepatoma cells were sectioned into $1 \mathrm{~mm}^{3}$ pieces. Tumor sections were transplanted into livers of nude mice, as described earlier. ${ }^{49}$ After 4 weeks, mice were treated with vehicle or doxorubicin $(10 \mathrm{mg} / \mathrm{kg}$ once per week, i.p). Cellular growth and metastasis of tumors were monitored once a week via IVIS. ${ }^{50}$ After 13 weeks, mice were killed, and the livers and lungs are collected.

Flow cytometric assay of apoptosis. Parental or derived hepatoma cells were treated with cisplatin, doxorubicin or r-TRAIL after stimulation with $\mathrm{T}_{3}(0$ or $10 \mathrm{nM})$ for $24 \mathrm{~h}$. Cells were harvested via trypsinization and fixed in ethanol/PBS $(7: 3, \mathrm{v} / \mathrm{v})$ for $1 \mathrm{~h}$ at $-20^{\circ} \mathrm{C}$. Subsequently, cells were washed with PBS and resuspended in PBS containing $40 \mu \mathrm{g} / \mathrm{ml}$ RNase A and $0.5 \%$ (v/v) Triton X-100 for $1 \mathrm{~h}$ at $37^{\circ} \mathrm{C}$. Finally, cells were pelleted and resuspended in PBS containing propidium iodide $(50 \mu \mathrm{g} / \mathrm{ml}$, Sigma). The extent of genomic DNA fragmentation was quantified via flow cytometric analysis of hypodiploid DNA. Data were collected and analyzed with FACScan (Becton Dickinson, San Jose, CA, USA) running the CellQuest software (Becton Dickinson, San Jose, CA, USA).

\section{Conflict of Interest}

The authors declare no conflict of interest.

Acknowledgements. This work was supported by grants from Chang Gung Memorial Hospital, Taoyuan, Taiwan (CMRPD1C0271, CMRPD1C0272, CMRPD1C0273) and from the Ministry of Science and Technology of the Republic of China (MOST103-2320-B182-018-MY3).

1. Pike MC, Spicer DV, Dahmoush L, Press MF. Estrogens, progestogens, normal breast cell proliferation, and breast cancer risk. Epidemiol Rev 1993; 15: 17-35.

2. Brawer MK. Hormonal therapy for prostate cancer. Rev Urol 2006; 8(Suppl 2): S35-S47.

3. Huang YH, Tsai MM, Lin KH. Thyroid hormone dependent regulation of target genes and their physiological significance. Chang Gung Med J 2008; 31: 325-334. 
4. Pilo A, lervasi G, Vitek F, Ferdeghini M, Cazzuola F, Bianchi R. Thyroidal and peripheral production of $3,5,3^{\prime}$-triiodothyronine in humans by multicompartmental analysis. $A m ~ J$ Physiol 1990; 258(Pt 1): E715-E726.

5. Huang YH, Tsai MM, Lin KH. Thyroid hormone dependent regulation of target genes and their physiological significance. Chang Gung Med J 2008; 31: 325-334.

6. Chan $\mathrm{IH}$, Privalsky ML. Thyroid hormone receptor mutants implicated in human hepatocellular carcinoma display an altered target gene repertoire. Oncogene 2009; 28: 4162-4174.

7. El-Serag HB, Rudolph KL. Hepatocellular carcinoma: epidemiology and molecular carcinogenesis. Gastroenterology 2007; 132: 2557-2576.

8. Sorvillo F, Mazziotti G, Carbone A, Morisco F, Cioffi M, Rotondi M et al. Increased serum reverse triiodothyronine levels at diagnosis of hepatocellular carcinoma in patients with compensated HCV-related liver cirrhosis. Clin Endocrinol (Oxf) 2003; 58: 207-212.

9. Chi HC, Chen CY, Tsai MM, Tsai CY, Lin KH. Molecular functions of thyroid hormones and their clinical significance in liver-related diseases. Biomed Res Int 2013; 2013: 601361.

10. Ledda-Columbano GM, Perra A, Concas D, Cossu C, Molotzu F, Sartori C et al. Different effects of the liver mitogens triiodo-thyronine and ciprofibrate on the development of rat hepatocellular carcinoma. Toxicol Pathol 2003; 31: 113-120.

11. Ledda-Columbano GM, Perra A, Piga R, Pibiri M, Loi R, Shinozuka $\mathrm{H}$ et al. Cell proliferation induced by $3,3^{\prime}, 5$-triiodo-L-thyronine is associated with a reduction in the number of preneoplastic hepatic lesions. Carcinogenesis 1999; 20: 2299-2304.

12. Chi HC, Chen SL, Liao CJ, Liao CH, Tsai MM, Lin YH et al. Thyroid hormone receptors promote metastasis of human hepatoma cells via regulation of TRAIL. Cell Death Differ 2012; 19: 1802-1814.

13. Youle RJ, Strasser A. The BCL-2 protein family: opposing activities that mediate cell death. Nat Rev Mol Cell Biol 2008; 9: 47-59.

14. Strasser A. The role of BH3-only proteins in the immune system. Nat Rev Immunol 2005; 5 : 189-200.

15. Chen L, Willis SN, Wei A, Smith BJ, Fletcher Jl, Hinds MG et al. Differential targeting of prosurvival $\mathrm{Bcl}-2$ proteins by their $\mathrm{BH} 3$-only ligands allows complementary apoptotic function. Mol Cell 2005; 17: 393-403.

16. U M, Miyashita T, Shikama Y, Tadokoro K, Yamada M. Molecular cloning and characterization of six novel isoforms of human Bim, a member of the proapoptotic Bcl-2 family. FEBS Lett 2001; 509: 135-141.

17. O'Connor L, Strasser A, O'Reilly LA, Hausmann G, Adams JM, Cory S et al. Bim: a novel member of the Bcl-2 family that promotes apoptosis. EMBO J 1998; 17: 384-395.

18. Ley R, Ewings KE, Hadfield K, Cook SJ. Regulatory phosphorylation of Bim: sorting out the ERK from the JNK. Cell Death Differ 2005; 12: 1008-1014.

19. Gillings AS, Balmanno K, Wiggins CM, Johnson M, Cook SJ. Apoptosis and autophagy: BIM as a mediator of tumour cell death in response to oncogene-targeted therapeutics. FEBS $J$ 2009; 276: 6050-6062.

20. Akiyama T, Dass CR, Choong PF. Bim-targeted cancer therapy: a link between drug action and underlying molecular changes. Mol Cancer Ther 2009; 8: 3173-3180.

21. Wang J, Zhou JY, Wu GS. Bim protein degradation contributes to cisplatin resistance. J Biol Chem 2011; 286: 22384-22392.

22. Yang $Y$, Zhao Y, Liao W, Yang J, Wu L, Zheng Z et al. Acetylation of FoxO1 activates Bim expression to induce apoptosis in response to histone deacetylase inhibitor depsipeptide treatment. Neoplasia 2009; 11: 313-324.

23. Gilley J, Coffer PJ, Ham J. FOXO transcription factors directly activate bim gene expression and promote apoptosis in sympathetic neurons. J Cell Biol 2003; 162: 613-622.

24. Zhao HH, Herrera RE, Coronado-Heinsohn E, Yang MC, Ludes-Meyers JH, Seybold-Tilson KJ et al. Forkhead homologue in rhabdomyosarcoma functions as a bifunctional nuclear receptor-interACTINg protein with both coactivator and corepressor functions. J Biol Chem 2001; 276: 27907-27912.

25. Accili D, Arden KC. FoxOs at the crossroads of cellular metabolism, differentiation, and transformation. Cell 2004; 117: 421-426.

26. Tran H, Brunet A, Griffith EC, Greenberg ME. The many forks in FOXO's road. Sci STKE 2003; 2003: RE5.

27. Lam EW, Francis RE, Petkovic M. FOXO transcription factors: key regulators of cell fate. Biochem Soc Trans 2006; 34(Pt 5): 722-726.

28. Zhang X, Tang N, Hadden TJ, Rishi AK. Akt, FoxO and regulation of apoptosis. Biochim Biophys Acta 2011; 1813: 1978-1986.

29. Hiroi Y, Kim HH, Ying H, Furuya F, Huang Z, Simoncini T et al. Rapid nongenomic actions of thyroid hormone. Proc Natl Acad Sci USA 2006; 103: 14104-14109.

30. Bandyopadhyay A, Wang L, Agyin J, Tang Y, Lin S, Yeh IT et al. doxorubicin in combination with a small TGFbeta inhibitor: a potential novel therapy for metastatic breast cancer in mouse models. PLoS One 2010; 5: e10365.

31. Jemal A, Bray F, Center MM, Ferlay J, Ward E, Forman D. Global cancer statistics. $C A$ Cancer J Clin 2011; 61: 69-90.
32. Park KW, Park JW, Choi JI, Kim TH, Kim SH, Park HS et al. Survival analysis of 904 patients with hepatocellular carcinoma in a hepatitis B virus-endemic area. J Gastroenterol Hepatol 2008; 23: 467-473.

33. $\mathrm{Cao} \mathrm{H}$, Phan $\mathrm{H}$, Yang LX. Improved chemotherapy for hepatocellular carcinoma. Anticancer Res 2012; 32: 1379-1386.

34. Frau C, Loi R, Petrelli A, Perra A, Menegon S, Kowalik MA et al. Local hypothyroidism favors the progression of preneoplastic lesions to hepatocellular carcinoma in rats. Hepatology 2015; 61: 249-259.

35. Hassan MM, Kaseb A, Li D, Patt YZ, Vauthey JN, Thomas MB et al. Association between hypothyroidism and hepatocellular carcinoma: a case-control study in the United States. Hepatology 2009; 49: 1563-1570.

36. Kress E, Skah S, Sirakov M, Nadjar J, Gadot N, Scoazec JY et al. Cooperation between the thyroid hormone receptor TRalpha1 and the WNT pathway in the induction of intestinal tumorigenesis. Gastroenterology 2010; 138: 1863-1874.

37. Martinez-Iglesias O, Garcia-Silva S, Tenbaum SP, Regadera J, Larcher F, Paramio JM et al. Thyroid hormone receptor beta1 acts as a potent suppressor of tumor invasiveness and metastasis. Cancer Res 2009; 69: 501-509.

38. Preston-Martin S, Pike MC, Ross RK, Jones PA, Henderson BE. Increased cell division as a cause of human cancer. Cancer Res 1990; 50: 7415-7421.

39. Farber E. Hepatocyte proliferation in stepwise development of experimental liver cell cancer. Dig Dis Sci 1991; 36: 973-978.

40. Columbano A, Shinozuka H. Liver regeneration versus direct hyperplasia. FASEB J 1996; 10: $1118-1128$.

41. Nakamura N, Ramaswamy S, Vazquez F, Signoretti S, Loda M, Sellers WR. Forkhead transcription factors are critical effectors of cell death and cell cycle arrest downstream of PTEN. Mol Cell Biol 2000; 20: 8969-8982.

42. Medema RH, Kops GJ, Bos JL, Burgering BM. AFX-like Forkhead transcription factors mediate cell-cycle regulation by Ras and PKB through p27kip1. Nature 2000; 404: 782-787.

43. Tran H, Brunet A, Grenier JM, Datta SR, Fornace AJ Jr., DiStefano PS et al. DNA repair pathway stimulated by the forkhead transcription factor FOXO3a through the Gadd45 protein. Science 2002; 296: 530-534.

44. Simpson CD, Anyiwe K, Schimmer AD. Anoikis resistance and tumor metastasis. Cancer Lett 2008; 272: 177-185.

45. Woods NT, Yamaguchi H, Lee FY, Bhalla KN, Wang HG. Anoikis, initiated by Mcl-1 degradation and Bim induction, is deregulated during oncogenesis. Cancer Res 2007; 67: 10744-10752.

46. Uehara N, Matsuoka $Y$, Tsubura A. Mesothelin promotes anchorage-independent growth and prevents anoikis via extracellular signal-regulated kinase signaling pathway in human breast cancer cells. Mol Cancer Res 2008; 6: 186-193.

47. Spallarossa P, Altieri P, Garibaldi S, Ghigliotti G, Barisione C, Manca V et al. Matrix metalloproteinase-2 and -9 are induced differently by doxorubicin in $\mathrm{H} 9 \mathrm{c} 2$ cells: The role of MAP kinases and NAD(P)H oxidase. Cardiovasc Res 2006; 69: 736-745.

48. Liao CS, Tai PJ, Huang YH, Chen RN, Wu SM, Kuo LW et al. Regulation of AKR1B1 by thyroid hormone and its receptors. Mol Cell Endocrinol 2009; 307: 109-117.

49. Gao YS, Chen XP, Li KY, Wu ZD. Nude mice model of human hepatocellular carcinoma via orthotopic implantation of histologically intact tissue. World J Gastroenterol 2004; 10: 3107-3111.

50. Liu SC, Tsang NM, Chiang WC, Chang KP, Hsueh C, Liang Y et al. Leukemia inhibitory factor promotes nasopharyngeal carcinoma progression and radioresistance. J Clin Invest 2013; 123: 5269-5283.

(i) Cell Death and Disease is an open-access journal published by Nature Publishing Group. This work is licensed under a Creative Commons Attribution 4.0 International License. The images or other third party material in this article are included in the article's Creative Commons license, unless indicated otherwise in the credit line; if the material is not included under the Creative Commons license, users will need to obtain permission from the license holder to reproduce the material. To view a copy of this license, visit http://creativecommons.org/licenses/by/4.0/

(C) The Author(s) 2016

Supplementary Information accompanies this paper on Cell Death and Disease website (http://www.nature.com/cddis) 